разработке объективных критериев обесценения, созданию резервов под обесценение финансовых вложений, резервов на реструктуризацию объединенного бизнеса. Важнейшим для рассмотрения является вопрос определения такого показателя, как гудвилл, формально характеризующего инвестиционную привлекательность образованной в ходе объединения компании: его оценка и переоценка, особенности распределения по единицам, генерирующим денежные средства.

$$
* * *
$$

1. Российская Федерация. Приказ. Методические указания по формированию отчетности при реорганизации организаций [Электронный ресурс]: федер. закон № 44н: принят Министерством Финансов РФ 20.05.2003 г. (в редакции от 25.10.2010 г. № 132н) // Консультант Плюс

2. Насакина Л.А. Методы сбора и анализа экономической информации в обосновании стратегических управленческих решений / Л.А. Насакина // Вестник Поволжского государственного университета сервиса. Серия: Экономика. 2012. № 24. С. 130-136.

3. Шнайдер О.В. Актуальные вопросы оценки стоимости бизнеса экономического субъекта / О.В. Шнайдер // Вопросы региональной экономики. 2017. Т. 31. № 2. С. 156-162.

\title{
Насакина Л.А. \\ Некоторые вопросы формирования управленческой учетной политики экономического субъекта
}

Поволжский государственный университет сервиса (ПВГУС)

(Россия, Тольятти)

doi:10.18411/spc-08-04-2018-19

idsp: 000001:spc-08-04-2018-19

\section{Аннотация}

Разработка управленческой учетной политики экономического субъекта представляет собой многоэтапный процесс, обеспечивающий создание фундаментальной основы осуществления управленческого учета и составления отчетности по отдельным структурным подразделениям организации. Управленческая учетная политика в отличие от учетной политики для целей финансового учета позволяет осуществлять подготовку более аналитической информации и устанавливать не только финансовые критерии оценки деятельности внутренних сегментов экономического субъекта, но и включать нефинансовые данные. Такой подход к разработке управленческой учетной политики обеспечивает эффективную организацию управленческого учета в экономическом субъекте и возможность использования его данных как для оперативного управления деятельностью организации и ее структурных подразделений, так и для установления стратегических ориентиров для будущей деятельности с учетом внутренних потребностей и новых вызовов внешней среды.

Ключевые слова: управленческий учет, учетная политика, внутренняя отчетность.

\section{Abstract}

Development of management accounting policy of an economic entity is a multi-stage process that provides the creation of a fundamental basis for the implementation of management accounting and reporting on individual structural units of the organization. Management accounting policies, unlike accounting policies for financial accounting purposes, allow for the preparation of more analytical information and establish not only financial criteria for assessing the activities of internal segments of an economic entity, but also to include non-financial data. This approach to the development of management accounting policy ensures the effective organization of management accounting in the economic entity and the ability to use its data for the operational management of the 
organization and its structural units, and to establish strategic guidelines for future activities, taking into account domestic needs and new challenges of the environment.

Keywords: management accounting, accounting policy, internal reporting.

Разработка управленческой учетной политики продиктована выделением в учетной системе экономического субъекта подсистемы управленческого учета, назначение и содержание которого оказывают влияние на специфику формирования этой учетной политики. Определяющими факторами при разработке управленческой учетной политики, также как и при разработке учетной политики для целей финансового учета являются адекватность и соответствие субъекта хозяйствования современным требованиям нормативно-законодательной базы по организации экономической деятельности, регламентация форм собственности, а также вопросы учета, отчетности и налогообложения. При этом следует учитывать и те факторы, которые являются воздействующими только на содержание управленческой учетной политики - это: особенности технико-технологических профилей экономического субъекта, его масштабность, организационно-правовая форма, функциональноспециализированный уровень. Основу для разработки управленческой учетной политики составляет система показателей, характеризующая деятельность предприятия в целом и его структурных подразделений, и количественно отражающая сформулированные цели собственников. Данные, получаемые в системе управленческого учета и определяемые подходами управленческой учетной политики, должны представлять собой более аналитическую информации и устанавливать не только финансовые критерии оценки деятельности внутренних сегментов, но и включать нефинансовые данные.

C учетом вышесказанного, управленческую учетную политикуможно определить как инструмент формирования информации финансового и нефинансового характера, которая должна определяться потребностями внутренних пользователей экономического субъекта и форматом внутренней отчетности, предназначенной для аккумулирования данных в целях принятия эффективных решений на разных уровнях управления. Обязательными требованиями, предъявляемыми к управленческой учетной политике является соблюдение принципов непрерывности и преемственности, способствующих реализации ее возможностей в интересах эффективного управления экономическим субъектом.

Следует отметить, что в настоящее время отсутствует единая методика формирования управленческой учетной политики. Поэтому при ее разработке считаем рациональным применять правила предоставления информации, удобные для внутренних пользователей экономического субъекта, а также исходя из требований действующих законодательных актов. Придерживаясь мнения таких ученыхэкономистов как Вахрушина М.А., Кондраков Н.П., Ляльковская Е.Е. и другие, рекомендуем при формировании управленческой учетной политики использовать за основу формат учетной политики для целей финансового учета. Принципы формирования учетной политики экономического субъекта определены Положением по бухгалтерскому учету «Учетная политика организации» ПБУ 1/2008, утвержденным Приказом Минфина РФ от 06.10.2008 N 106н [4].

Основное место в управленческой учетной политике занимают вопросы учета затрат и формирования себестоимости продукции (работ, услуг) составляющие содержание производственного учета. Принципы формирования состава себестоимости определены Налоговым Кодексом РФ (часть II, глава 25) и Положением по бухгалтерскому учету «Расходы организации» ПБУ 10/99 от 06.05.1999г. №33н (ред. от 06.04.2015г.).

Разрабатывая управленческую учетную политику, важно обозначить существующую взаимосвязь управленческого и финансового учета, которая 
проявляется в том, что одни и те же хозяйственные операции одновременно отражаются в обеих подсистемах и при этом основанием для их отражения являются одни и те же первичные документы. Только отличается общий подход к порядку отражения соответствующих хозяйственных операций в финансовом и управленческом учете. В частности, в финансовом учете затраты отражаются в разрезе отдельных их видов - в разрезе элементов затрат без принадлежности затрат к какому-либо объекту калькулирования, а в управленческом учете - по статьям калькуляции в разрезе отдельных видов продукции (работ, услуг) или по местам их возникновения [1].

Обозначенная взаимосвязь между финансовым и управленческим учетом обуславливает схожесть учетной политики для целей финансового учета и управленческой учетной политики относительно их поэлементной структуры [2]. Но при этом имеют место отличия между содержанием учетной политики для целей финансового учета и управленческой учетной политики, которые в общем виде представлены в таблице 1.

Таблийа 1

Сравнительная оценка элементов учетной политики в системе финансового и управленческого учета

\begin{tabular}{|c|c|c|}
\hline Элементы учетной политики & $\begin{array}{c}\text { Учетная политика для } \\
\text { целей финансового учета }\end{array}$ & $\begin{array}{c}\text { Учетная политика для целей } \\
\text { управленческого учета }\end{array}$ \\
\hline $\begin{array}{c}\text { Порядок отражения } \\
\text { хозяйственных операций }\end{array}$ & Двойная запись & Простая запись; двойная запись \\
\hline $\begin{array}{c}\text { Определение даты отражения } \\
\text { хозяйственной операции }\end{array}$ & За отчетный период & $\begin{array}{c}\text { В день осуществления операции, на } \\
\text { следующий день после } \\
\text { осуществления операции }\end{array}$ \\
\hline $\begin{array}{c}\text { Основание для отражения в } \\
\text { учете }\end{array}$ & $\begin{array}{c}\text { Бухгалтерские первичные } \\
\text { документы }\end{array}$ & $\begin{array}{c}\text { Бухгалтерские первичные документы, } \\
\text { расчетные показатели }\end{array}$ \\
\hline $\begin{array}{l}\text { Определение даты получения } \\
\text { дохода }\end{array}$ & Метод начисления & Метод начисления и кассовый метод \\
\hline $\begin{array}{c}\text { Метод учета затрат и } \\
\text { калькулирования себестоимости }\end{array}$ & $\begin{array}{c}\text { Метод полных и } \\
\text { неполных затрат, } \\
\text { калькуляция фактической } \\
\text { себестоимости }\end{array}$ & $\begin{array}{c}\text { Попроцессный, попередльный, } \\
\text { показаный метод, калькуляция } \\
\text { нормативной и фактической } \\
\text { себестоимости }\end{array}$ \\
\hline $\begin{array}{c}\text { Определение лимита стоимости } \\
\text { долгосрочного имущества, } \\
\text { подлежащего учету в составе } \\
\text { МП3 }\end{array}$ & $\begin{array}{c}\text { Все объекты средств труда } \\
\text { с длительным периодом } \\
\text { использования не более } \\
40000 \text { руб. }\end{array}$ & $\begin{array}{c}\text { Все объекты средств труда с } \\
\text { длительным периодом использования } \\
\text { не более } 40000 \text { руб. }\end{array}$ \\
\hline $\begin{array}{c}\text { Порядок и способы погашения } \\
\text { стоимости основных средств }\end{array}$ & $\begin{array}{c}\text { Посредством начисления } \\
\text { амортизации в } \\
\text { соответствии с ПБУ 6/01 }\end{array}$ & $\begin{array}{c}\text { Посредством начисления амортизации } \\
\text { в соответствии с ПБУ 6/01 }\end{array}$ \\
\hline $\begin{array}{c}\text { Порядок определения учетной } \\
\text { цены }\end{array}$ & $\begin{array}{l}\text { По фактической } \\
\text { себестоимости }\end{array}$ & По плановым и расчетным ценам \\
\hline Состав и классификация затрат & По элементам затрат & По статьям калькуляции \\
\hline
\end{tabular}

Одним из элементов управленческой учетной политики является выбор варианта организации управленческого учета, предусматривающий схему осуществления учетных записей в бухгалтерии финансового учета и бухгалтерии управленческого учета. В условиях одного варианта имеет место однокруговая схема ведения учета, при которой предполагает ведение общего счетного плана с выделением в нем отдельного раздела счетов для управленческого учета. При другом варианте - используется двухкруговая схема учета, согласно которой разрабатывают и ведут раздельные счетные планы для отражения операций в финансовом и управленческом учете. Обмен информацией между финансовой и управленческой бухгалтерией может осуществляться черезпосредством счета 79 «Внутрихозяйственные расчеты», который в этом случае выполняют функцию передачи информации. При двухкруговой системе в финансовом учете затраты отражаются в разрезе отдельных их видов без указания принадлежности затрат к какому-либо объекту учета, а в управленческом учете - в 
учетных записях отражается информация в более аналитическом разрезе, что позволяет установить место возникновения затрат и их отнесение на конкретный объект учета. При такой схеме учетных записей обмен данными между разными бухгалтериями производится посредством использования отражающих счетов (счетов-экранов), в качестве которых могут быть выделены свободные коды счетов из типового плана счетов бухгалтерского учета: счёт 30 «Материальные затраты», счёт 31 «Затраты на оплату труда», счёт 32 «Страховые взносы», счёт 33 «Амортизация», счёт 34 «Прочие затраты».

Рассмотренные возможные положения управленческой учетной политики не являются окончательно регламентированными - экономические субъекты могут вносить дополнительные разделы в зависимости от особенностей техникотехнологических профилей субъекта хозяйствования, его масштабности, организационно-правовой формы, функционально-специализированного уровня, а также целей и задач, стоящих перед экономическим субъектом в ближайшей и долгосрочной перспективе. Но даже те положения, которые нами рекомендованы при разработке управленческой учетной политики определяют основу эффективной организации управленческого учета в экономическом субъекте и установления стратегических ориентиров для будущей деятельности с учетом внутренних потребностей и новых вызовов внешней среды.

$$
* * *
$$

1. Васильчук, О.И. Методические аспекты внутрихозяйственного контроля системы бизнес-процессов [Текст] / О.И. Васильчук // Азимут научных исследований: экономика и управление. 2014. № 1. С. $19-22$.

2. Медведева, Е.В. Регламентация учетной политики в российской и международной практике [Текст] / Е.В. Медведева // В сборнике материалов Международной научно-практической конференции «Современное состояние и перспективы развития бухгалтерского учета, экономического анализа и аудита». 2016. С. 29-34.

3. Неизвестная, Д.В. Формирование учетной политики для целей сегментарного учета [Текст] / Д.В. Неизвестная // Вестник экономики, права и социологии. 2013. № 1. С.84-87.

4. Об утверждении Положение по бухгалтерскому учету «Учетная политика организации» ПБУ 1/08 [Электронный ресурс] : № 106н : Приказ Минфина РФ от 06.10.2008г. / ЗАО «Консультант Плюс». - ИБ СПС Консультант Плюс.

\section{Нехорошева К.И.}

Валютные риски в коммерческом банке: сущность и механизм управления

Северо-Кавказский федеральный университет (Россия, Ставрополь)

doi:10.18411/spc-08-04-2018-20

idsp: 000001:spc-08-04-2018-20

\section{Аннотация}

В данной работе раскрыта сущность и понятие валютного риска, и рассмотрены механизмы управления валютным риском. Также представлены операции, на управление которыми направлен риск-менеджмент.

Ключевые слова: Валютный риск, управление валютным риском, рискменеджмент

Успешная реализация банковской деятельности связана с важностью четкого понимания сущности рисковой ее составляющей, в том числе в области валютного риска, где глубокая теоретическая проработка многих вопросов, связанных с определением экономических основ механизма его управления обуславливает наличие определенных конкурентных преимуществ на современном валютном рынке как общемирового центра кооперации всей финансовой деятельности.

В научных публикациях освещены разносторонние взгляды на типологию и место валютных рисков, но при всей значимости разработок из-за сложности и 